\title{
Glycoprotein Degradation in the Blind Loop Syndrome
}

\author{
IDENTIFICATION OF GLYCOSIDASES IN JEJUNAL CONTENTS
}

\author{
Roberto Prizont, Department of Medicine, Section of Gastroenterology, \\ Veterans Administration Medical Center and University of New Mexico, \\ Albuquerque, New Mexico 87108
}

\begin{abstract}
A B S T RACT Contents obtained from jejunum of normal controls, self-emptying and self-filling blind loop rats were analyzed for the presence of glycoprotein-degrading glycosidases. The blind loop syndrome was documented by the increased fat excretion and slower growth rate of self-filling blind loop rats $6 \mathrm{wk}$ after surgery. With $p$-nitrophenylglycosides as substrate, the specific activity of $\alpha-N$-acetylgalactosaminidase, a potential blood group A destroying glycosidase, was $0.90 \pm 0.40 \mathrm{mU} / \mathrm{mg}$ of protein. This level was 23 fold higher than the specific activity of normal controls. In partially purified self-filling blind loop contents, the activity of $\alpha-N$-acetylgalactosaminidase was 9 - to 70fold higher than activities of self-emptying and normal controls. Antibiotic treatment with chloromycetin and polymyxin decreased 24 -fold the glycosidase levels in self-filling blind loops. In experiments with natural substrate, the blood group A titer of a $20,000 \mathrm{~g}$ supernate from normal jejunal homogenates decreased 128 -fold after 24-h incubation with blind loop contents. Normal contents failed to diminish the blood group reactivity of the natural substrate. Furthermore, blind loop contents markedly decreased the blood group A titer of isolated brush borders. Incubation between blind loop bacteria and mucosal homogenates or isolated brush borders labeled with $\mathrm{D}-\left[\mathrm{U}-{ }^{14} \mathrm{C}\right]$ glucosamine revealed increased production of labeled ether extractable organic acids. Likewise, intraperitoneal injection of $\mathrm{D}-\left[\mathrm{U}-{ }^{14} \mathrm{C}\right] \mathrm{glucosamine}$ into self-filling blind loop rats resulted in incorporation of the label into luminal short chain fatty acids. These results suggest that glycosidases may provide a mechanism by which blind loop bacteria obtain sugars from intestinal glycoproteins. The released sugars are used and converted by bacteria
\end{abstract}

This paper was presented in part at the Regional Meeting of the American Federation of Clinical Research, February 1978, Carmel, Calif. and at the National American Gastroenterological Association Meeting, May 1978, Las Vegas, Nev.

Received for publication 22 November 1978 and in revised form 29 September 1980. into energy and organic acids. This use of the host's glycoproteins would allow blind loop bacteria to grow and survive within the lumen independent of exogenous sources.

\section{INTRODUCTION}

Blood group-degrading enzymes produced by fecal bacteria from conventional rats and normal individuals have been shown to modify the blood group antigenicity of hog gastric mucin by removing terminal sugars of the oligosaccharide chains $(1,2)$. Recently, we have identified a similar blood group B-degrading enzyme in cecal contents of normal rats. When tested against the cecal glycoprotein, it actively destroyed the blood group antigenicity of the appropriate biological substrate. Using synthetic substrates, we also found a variety of active nonblood group ABO-degrading glycosidases (3). Cecal blood group and nonblood group-degrading glycosidases appear to derive from the normal cecal microflora because similar contents of germ-free rats were relatively free of these enzymes.

Recent reports suggest abnormalities of the small intestinal cells in the blind loop syndrome. In this pathological condition the lumen of the small bowel is contaminated with colonic type bacteria $(4,5)$. Electron microscopic studies of the small bowel mucosa of these patients revealed a decrease in the number of enterocytes involved in the absorption of dietary fat (6). In addition, this study showed a delay in the exit of chylomicrons from intestinal cells. Giannella et al. (7) found that the levels of brush border disaccharidases and the uptake of 3-O-methyl-glucose and L-leucine was significantly decreased in small bowel homogenates and everted jejunal rings of blind loop rats.

The chief organic constituent of the intestinal mucus secreted by goblet cells consists of a glycoprotein that contains up to $85 \%$ carbohydrates (8). The carbohydrate content of the underlying brush border glycoprotein is lower than that of the secretory mucus (9). 
It may be assumed that in the event of bacterial overgrowth of the small intestine the oligosaccharide chains of surface glycoproteins would become susceptible to degradation by the luminal microorganisms. The degrading enzymes that have been found in normal feces and cecal content may similarly be produced by blind loop bacteria, and thus, the oligosaccharide chains of small intestinal glycoproteins might be exposed to a number of degrading glycosidases.

The first objective of this study was to identify glycosidases in the luminal content of the experimental blind loop rat. A subsequent aim was to establish whether blind loop glycosidases are of intestinal and/or bacterial origin. The final purpose of the investigation was to determine the hydrolytic capability of these enzymes on the natural glycoprotein.

\section{METHODS}

Male Sprague Dawley rats (Charles River, Breeding Laboratories, Wilmington, Mass.), from 200 to $300 \mathrm{~g}$ in weight were used as control and experimental animals. After an overnight fast and under ether anesthesia, the rat abdomen was opened by a midline incision. The ligament of Treitz was identified and the jejunum transected $4 \mathrm{~cm}$ beyond the duodenojejunal flexure. A 9-cm self-filling blind loop was created by closing the loop with separated stitches as described by Lambert (10). In another group of rats, a $9-\mathrm{cm}$ self-emptying blind loop was created $10 \mathrm{~cm}$ from the ligament of Treitz. Before closing the abdomen, $4 \mathrm{mg}$ of streptomycin and 50,000 $\mathrm{U}$ of procaine penicillin $\mathrm{G}$ was delivered to the peritoneal cavity. Rats were allowed only water for $48 \mathrm{~h}$ postsurgery and then returned to regular feeding. Animals were kept in conventional cages and fed a chow laboratory diet in pellet form with drinking water ad lib. After an interval of 2 wk postsurgical recovery, the growth of control and operated animals was followed for a 4-wk period. For metabolic studies, control, and operated rats who had surgery at least 1 mo earlier were transferred to metabolic cages. Rats were fed a powdered Wayne Laboratory animal diet obtained from Allied Mills, Inc. (Chicago, Ill.). The diet contained $47.5 \%$ carbohydrates, $22 \%$ protein, and $5 \%$ fat. For a period of $1 \mathrm{wk}$, caps containing the food were weighed daily and the consumption recorded.

A group of rats with self-filling blind loops was subjected to an antibiotic trial for $5 \mathrm{~d}$. Chloromycetin $(0.72 \mathrm{~g})$ and polymyxin B $(28 \mathrm{mg})$, were added to the drinking water bottles. Control and operated rats underwent metabolic studies at the same interval of time. Stools from each rat were collected periodically, placed in individual polyethylene plastic bags, and stored at $-25^{\circ} \mathrm{C}$.

Collection of intestinal samples. To obtain jejunal fluid, normal and operated rats were fasted overnight, anesthetized lightly with ether, and killed by decapitation. Experiments were then carried out at $0^{\circ}-4^{\circ} \mathrm{C}$. The small bowel was exteriorized by placing ligatures at the pylorus and ileum to avoid fluid shifts between stomach and small intestine and colon and small intestine. The blind loop pouch was then identified and separated. In normal rats, a segment of $10 \mathrm{~cm}$ located immediately beyond the ligament of Treitz was chosen as comparable to the blind loop pouch. The content of the sampling sites were washed out with $12 \mathrm{ml}$ ice cold $0.9 \% \mathrm{NaCl}$ containing $0.02 \%$ sodium azide for bacteriostasis. Jejunal contents from normal and operated rats were collected in preweighed centrifuge tubes, centrifuged at $500 \mathrm{~g}$ to remove debris and recentrifuged at $15,000 \mathrm{~g}$ to sediment bacteria. Bacterial free supernates were stored at $-25^{\circ} \mathrm{C}$.

Jejunal glycoproteins were obtained from another group of normal rats. The small bowel was separated in toto from the pylorus to $20 \mathrm{~cm}$ proximal to the ileocecal valve, flushed with cold saline, everted on a chilled glass rod, dried, and the mucosa scraped with a cover slide. The scraped mucosa, containing a mixture of glycoproteins and cells, was weighed, diluted 1.5 times $\mathrm{wt} / \mathrm{vol}$ with saline, and homogenized in a Potter-Elvenhjem tissue homogenizer. The homogenate was centrifuged at $20,000 \mathrm{~g}$ for $10 \mathrm{~min}$ (11), and the supernate was used for hemagglutination inhibition studies. For the brush border preparation, the weighed mucosa was dissolved in $75 \mathrm{vol}$ of $5 \mathrm{mM}$ EDTA buffer than had been adjusted to pH 7.4. The dissolved mucosa was then homogenized for $25 \mathrm{~s}$ and centrifuged at $450 \mathrm{~g}$. The washed sediment was resuspended in $90 \mathrm{mM} \mathrm{NaCl}$ plus $0.8 \mathrm{mM}$ EDTA, passed through glass wool, and recentrifuged. The final sediment was resuspended in EDTA and was called "purified brush border" as described by Forstner (12).

In two experimental animals, mucosa was obtained from the blind loop segment as well as from segments $10 \mathrm{~cm}$ proximal and distal to the blind loop. The mucosa was weighed, homogenized, and brush borders purified as described earlier. In another experimental group of three animals, the homogenized mucosa was centrifuged as before to obtain clear supernates. Purified brush borders and clear supernate were tested for blood group antigenicity by the hemagglutination inhibition reaction and assayed for protein.

In the next set of experiments, normal rats were injected intraperitoneally with $5-20 \mu \mathrm{Ci}$ of $\mathrm{D}-\left[\mathrm{U}-{ }^{14} \mathrm{C}\right]$ glucosamine hydrochloride (New England Nuclear, Boston, Mass.). After a 3-h interval (13), rats were sacrificed, the small intestinal mucosa scraped, weighed, and homogenized in cold saline to obtain whole labeled mucosal homogenates. Labeled brush borders were purified from a similar group of injected rats. Radioactively labeled homogenates and isolated brush borders were used for incubation with bacteria of selffilling blind loops. Bacteria were obtained by washing contents of self-filling loops with cold saline under an oxygenfree $\mathrm{CO}_{2}$ atmosphere. Washed contents were centrifuged at $15,000 \mathrm{~g}$ and the bacterial pellets resuspended in $2 \mathrm{ml}$ of Tris-Kreb's buffered solution of $\mathrm{pH} 7.4$. Aliquots of the bacterial suspensions were serially diluted in saline, plated on Bacto agar (Difco Laboratories, Detroit, Mich.), and cultured aerobically and anaerobically in a Gas Pak anaerobic system (Ferguson Industries, Dallas Tex.). Colonies were counted under naked eye and identified by gram stain and the API system (Analytab Products, Plainview, N. Y.).

In the final set of experiments, $15-20 \mu \mathrm{Ci}$ of $\mathrm{D}-\left[\mathrm{U}-{ }^{14} \mathrm{C}\right]-$ glucosamine hydrochloride were injected intraperitoneally into self-filling blind loop rats. Animals were killed and the blind loop contents were collected and processed as previously described. The volumes of bacteria-free supernates were measured, and aliquots removed and extracted into ether for short chain fatty acid analysis.

Incubation of radioactive mucosa with bacteria. Bacterial suspension obtained from self-filling blind loops were incubated with labeled homogenate or isolated brush border preparations in a total assay volume of 20-25 $\mathrm{ml}$. Three experiments were performed with each radioactive intestinal sample. The mixtures containing $50 \mathrm{mg}$ of cysteine were flushed with oxygen-free $\mathrm{CO}_{2}$ and placed in a shaking incubator at $37^{\circ} \mathrm{C}$. At increasing intervals of time, 2 -ml aliquots were removed and placed on an ice bath. The samples were centrifuged at $15,000 \mathrm{~g}$ to separate sedimentable in- 
testinal constituents and bacteria. Clear supernatants were acidified with $50 \%$ sulfuric acid, extracted into $1 \mathrm{ml}$ of diethyl ether, and frozen at $-25^{\circ} \mathrm{C}$. The ether was removed from the frozen aqueous layer and $0.5 \mathrm{ml}$ was transferred to a tube containing $40 \mu \mathrm{l}$ of $4 \mathrm{~N} \mathrm{NaOH}$. The remainder of the ether layer was added to a tube that contained the same amount of sodium hydroxide, plus a drop of phenolphthalein, as a test for alkalinity (14). The ether was then allowed to evaporate. The dried residue was redissolved into $0.5 \mathrm{ml}$ of distilled water, added to vials containing scintillation fluid, and counted in a Packard Tri-Carb scintillation spectrometer (Packard Instrument Co., Inc., Downers Grove, Ill.). This last alkaline extraction selectively excludes long chain fatty acids and glycolipids.

Bacteria and brush borders obtained by the $15,000 \mathrm{~g}$ centrifugation were resuspended in Krebs-Tris buffer $\mathrm{pH} 7.4$ and centrifuged at $450 \mathrm{~g}$ to collect the isolated brush borders. Sedimented brush borders were resuspended, aliquots counted for radioactivity, and tested for blood group antigenicity and sucrase activity. Sucrase activity of the incubated brush borders was measured by the method of Dahlqvist (15). Units of activity were expressed as micromoles of sucrose split per minute per gram (wet weight) of tissue. In some aliquots, brush borders were hydrolyzed for $6 \mathrm{~h}$ with $6 \mathrm{~N}$ $\mathrm{HCl}$ in a boiling water bath. After drying overnight, samples were reconstituted in distilled water and passed through a Dowex (Dow Corning Corp., Midland, Mich.) $50 \mathrm{H}^{+}$column. Hexosamines were eluted with $1 \mathrm{~N} \mathrm{HCl}$, neutralized with sodium hydroxide and counted for ${ }^{14} \mathrm{C}$ label.

Supernates of $450 \mathrm{~g}$ centrifugation were recentrifuged at $20,000 \mathrm{~g}$ to obtain a bacterial pellet. Bacterial pellets were resuspended in normal saline, disrupted by sonication, and centrifuged. The clear supernates were then used for counting.

Glycosidase assay. Clear supernatants from jejunal contents of normal and operated rats were thawed and used for glycosidase measurements. The $p$-nitrophenylglycoside substrate for $\beta-N$-acetylglucosaminidase was purchased from Sigma Chemical Co. (St. Louis, Mo.). The $p$-nitrophenylglycoside for $\alpha-N$-acetygalactosaminidase was obtained from Research Products International Corp. (Elk Grove Village, Ill.). The assay consisted of $0.1 \mathrm{ml}$ of $10 \mathrm{mM}$ solution of the $p$-nitrophenylglycoside, $0.3 \mathrm{ml}$ of $0.05 \mathrm{M}$ citrate buffer of $\mathrm{pH}$ 5.5 , and $0.1 \mathrm{ml}$ of jejunal sample in a total volume of $0.5 \mathrm{ml}$ (16). After $15-30 \mathrm{~min}$ incubation at $30^{\circ} \mathrm{C}$, the reaction was stopped by addition of sodium carbonate, and $p$-nitrophenol concentration was determined at $420 \mathrm{~nm}$. Units of enzyme activity were defined as micromoles of $p$-nitrophenol released per minute at $30^{\circ} \mathrm{C}$.

Clear supernates of blind loop segments and jejunum were partially purified by adding $65 \%$ saturation of ammonium sulfate to the samples. The suspension was mixed intermittently and centrifuged at $30,000 \mathrm{~g}$. The precipitated glycosidases were redissolved in equal volumes of citrate buffer and dialyzed.

Hemagglutination inhibition. Mucosal supernates and brush border preparations were incubated with bacteriafree supernates of self-filling blind loops at $30^{\circ} \mathrm{C}$. The reaction was stopped by boiling the mixture. After cooling the preparation, intestinal glycoproteins were tested for blood group antigenicity. Intestinal preparations $(0.05 \mathrm{ml})$ were serially diluted in saline $(0.05 \mathrm{ml})$. After incubation with two hemagglutinating units of antisera A, erythrocytes were added to the mixture. End point agglutination was determined by microscopy.

Short-chain fatty acid (SCFA)' determinations. Ether

${ }^{1}$ Abbreviation used in this paper: SCFA, short chain fatty acid. extractable materials were neutralized as before, and the ether was allowed to evaporate at room temperature. Dry residues were acidified with $\mathrm{H}_{2} \mathrm{SO}_{4}$ and re-extracted into ether. In another aliquot, a known amount of caproic acid was added as an internal standard and extracted as before. Samples were injected into a gas chromatograph for analysis.

Peak areas of the blind loop SCFA were related to the peak area of the known internal standard. In a previously published study we demonstrated that equivalent weights of all SCFA produced nonequivalent peak areas (17), due to nonuniform volatility, differential extractibility into ether and unequal detector response. Peak areas and radioactive counts of each acid were corrected by the following formula: ${ }^{\text {RSCFA }}=$ peak area or disintegrations per minute of internal standard/peak area or disintegrations per minute of sample acid. ${ }^{\mathrm{R} S C F A}$ were as follows: acetic acid 10.01; propionic acid 2.72 ; butyric acid 1.40 ; isovaleric acid 0.88 ; valeric acid 0.90

A Perkin-Elmer model sigma 3 gas chromatograph (PerkinElmer Corp., Instrument Div. Norwalk, Conn.) equipped with a flame ionization detector was used in this study. A glass column $(6 \mathrm{ft} \times 1 / 4 \mathrm{in}$.) was packed with $5 \%$ FFAP on Chromosorb G AW, DMCS, 70/80 mesh (Varian Associates, Inc., Palo Alto, Calif.). To collect radioactivity, the chromatograph was equipped with a simultaneous detector kit to split the effluent stream. Effluents were collected in a cold trap, thoroughly washed and placed in vials for counting.

Fat and protein determination. Fecal fat was determined by the method of van der Kamer (18). Results were expressed as the percentage of dietary fat excreted in feces in $24 \mathrm{~h}$. Concentration of protein was assessed by the method of Lowry et al. (19).

Statistical analysis. Differences in fat excretion among the three group of animals were evaluated by the Student's $t$ test. Comparisons of glycosidase values between blind loop and jejunal contents were performed by using the nonparametric Mann-Whitney test (20).

\section{RESULTS}

The development of the blind loop syndrome was monitored by fecal fat balance studies and weight curve comparisons of control and experimental animals.

Feces of self-filling blind loop rats contained a mean of $15.7 \pm 1.7 \%$ of the daily dietary fat intake. That was significantly higher than the $7.2 \pm 1.8 \%$ of self-emptying blind loop operated animals $(P<0.02)$ and the $6.5 \pm 0.7 \%$ excreted in $24 \mathrm{~h}$ by normal control rats $(P<0.005)$.

After the postsurgical recovery, self-filling blind loop rats grew very slowly. In a month they gained only an average of $67.6 \pm 10.3 \mathrm{~g}$ in weight. In a similar interval of time, self-emptying blind loop-operated and normal rats increased $100 \pm 8.0 \mathrm{~g}(P<0.05)$ and $131 \pm 7.0 \mathrm{~g}$ $(P<0.001)$ in weight, respectively.

Glycosidase activities. Specific activity of $\alpha-N$ acetylgalactosaminidase in bacteria-free supernates of self-filling blind loop segments was $0.91 \pm 0.40 \mathrm{mU} / \mathrm{mg}$ of protein. This level was 23-fold higher than the specific activity of this enzyme recovered from normal contents $(P<0.02)$. The activity of $\beta$ - $N$-acetylglucosaminidase, a nonblood group-degrading enzyme, showed a 22 -fold increase in contents of blind loop rats. 
In the second portion of these experiments, $\alpha-N$ acetylgalactosaminidase was measured in experimental contents after partial purification by ammonium sulfate precipitation and dialysis (Table I). $\alpha$ - $N$-acetylgalactosaminidase showed an activity that was 9 - to 70 -fold higher in self-filling blind loop segments than the activity recovered from self-emptying blind loop and normal control animals. After treatment with the mixtures of antibiotics, the glycosidase value of selffilling blind loop contents decreased from 10-fold to undetectable levels. Among the controls, self-emptying blind loop rats showed significantly higher glycosidase levels. This difference was due largely to the very low or unmeasurable activity in normal and antibiotic treated rats. It is also possible that some mild bacterial contamination occurred in the self-emptying blind loops. In any case, the enzyme levels run parallel to the intermediate growth and fat excretion of the selfemptying blind loop animals.

Enzyme degradation of mucosal supernates. The degrading ability of the glycosidases against natural glycoproteins was tested by incubating bacteria-free supernates of self-filling blind loop and normal contents with $20,000-g$ supernates of jejunal homogenates from normal rats. An average of three experiments was performed in each group. After a lag period of $2 \mathrm{~h}$, contents from blind loop rats steadily destroyed the blood group A antigenicity of the normal mucosal supernate, reaching a maximum of 128 -fold decrease at $24 \mathrm{~h} \mathrm{(Fig.} \mathrm{1).} \mathrm{Conversely,} \mathrm{normal} \mathrm{contents} \mathrm{did} \mathrm{not}$ alter the blood group antigenicity of the jejunal supernate, even after long periods of incubation. As noted, the blind loop glycosidase required a certain time of exposure to the jejunal glycoproteins to degrade the mucosal blood group antigenicity. This finding corroborates previous observations of the action of various glycosidases on natural glycoproteins. Spiro (21) considers several days of incubation under toluene are

TABLE I

Glycosidase Activities of Normal and Experimental Rats

\begin{tabular}{lc}
\hline & $\begin{array}{c}\alpha-N \text {-Acetylgalac- } \\
\text { tosaminidase* }\end{array}$ \\
\hline Self-filling blind loop (6) & $m U / m l$ \\
Normal (5) & $14.6 \pm 3.2$ \\
Self-emptying blind loop (5) & $0.19 \pm 0.03 \ddagger$ \\
Antibiotic treated (4) & $1.6 \pm 0.4 \ddagger$ \\
\end{tabular}

\footnotetext{
* Mean \pm SE.

$\ddagger P<0.01$; comparisons were made between normal or selfemptying blind loop and self-filling blind loop rats.

$\$ P<0.02$; comparisons were made between antibiotic treated and self-filling blind loop rats.
}

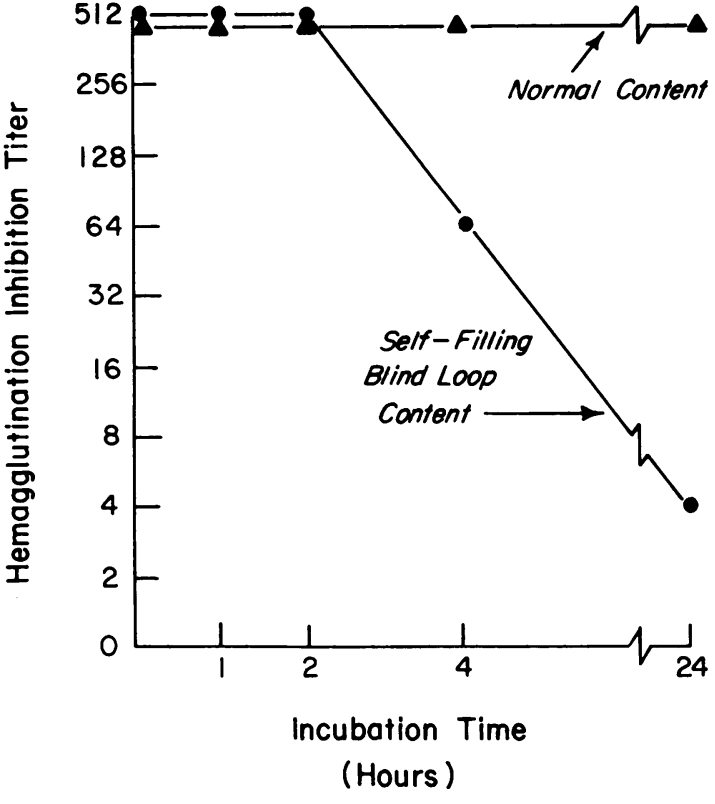

FIGURE 1 Degradative effect of partially purified normal and self-filling blind loop contents on blood group $\mathrm{A}$ reactivity of normal crude $20,000 \mathrm{~g}$ jejunal supernates. Hemagglutination inhibition titer of the oridinate represents the $n$ dilutions of the jejunal antigen.

necessary to assess fully the hydrolyzing activity of glycosidases against complex glycoprotein structures.

Enzyme degradation of brush borders. In the previous experiment we largely examined the glycosidase action on the crude cytoplasmic glycoproteins. In the following experiment, brush borders of normal jejunum were used as natural glycoproteins. As with mucosal supernates, bacteria-free supernates of self-filling blind loop contents markedly decreased the blood group A titer of purified brush border preparation (Fig. 2). In this situation, the lag period was shorter and the slope of the degradation curve more pronounced, suggesting a more rapid enzymatic action. Normal contents had negligible activity, decreasing the blood group titer in only one agglutination tube. This slight decrease in the brush border antigenicity is likely due to the inherent variation in the hemagglutination method. Determination of blood group A antigenicity in purified brush borders of self-filling blind loops revealed no significant changes in the hemagglutination inhibition as compared to proximal and distal segments. Mucosal supernates of blind loop segments similarly revealed little differences in blood group antigenicity as compared to adjacent regions. Protein concentration, however, appeared to be slightly elevated in brush borders of blind loop pouches.

Metabolism of released sugars. It was reasoned that if blind loop bacteria remove sugars from the mucosa, they would utilize and transform the carbo- 


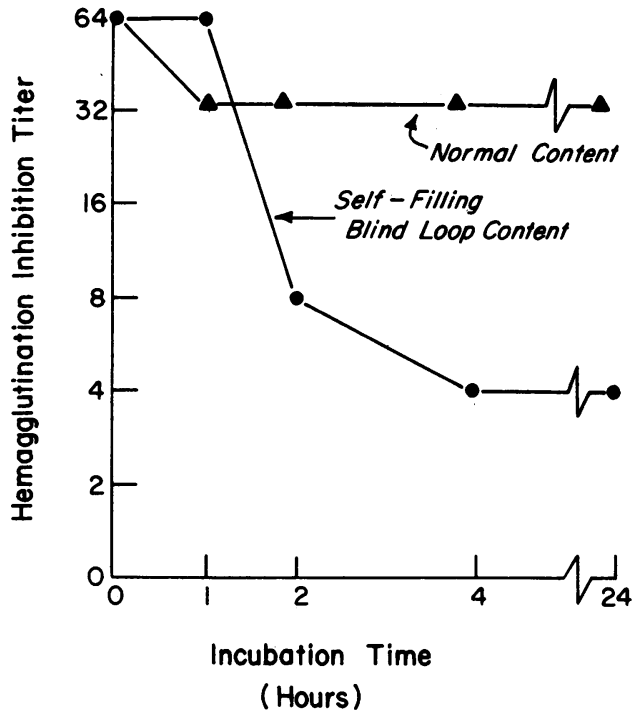

FIGURE 2 Decrease of blood group A antigenicity of purified jejunal brush border from a normal rat by action of partially purified normal and self-filling blind loop contents. Hemagglutination inhibition titer of the ordinate represents the number of dilutions of the jejunal antigen.

hydrates into bacterial metabolites. Transformation of carbohydrates by bacteria lead to the formation of fermentative acids, largely SCFA (22). These SCFA have been shown to be highly increased in blind loop contents (14). Thus, blind loop bacteria were incubated with whole mucosal homogenates or brush borders. Cultures of contents obtained from loop pouches rendered $8.3 \pm 0.6$ aerobes and $8.8 \pm 0.7$ anaerobes $/ \mathrm{ml}$ of fluid (expressed as logs of base 10). This concentration of anaerobes in self-filling blind loop pouches is similar to the recovery of anaerobes reported by other authors $(5,7)$. Anaerobes identified were largely gram-negative rods belonging to the genus bacteroides. Incubation of normal mucosal homogenates labeled with $\left[{ }^{14} \mathrm{C}\right]$ glucosamine with blind loop bacteria resulted in an increased production of ether extractable organic acids (Fig. 3A). Bacteria needed a lag period of $\sim 24 \mathrm{~h}$ to incorporate the radioactivity into the organic acids. The peak incorporation occurred between 48 and $74 \mathrm{~h}$ of incubation.

The incorporation of mucosal radioactivity into metabolites was similarly increased when bacteria were incubated with labeled purified brush border (Fig. 3B). The labeled ether extractable organic acids already appeared in considerable amounts after $4 \mathrm{~h}$ of incubation, suggesting increased degradation and transformation of the brush border glycoproteins.

2 or $3 \%$ of radioactivity was recovered in the blind loop bacterial pellet (Fig. 4C), reflecting residual radioactivity from the metabolism of carbohydrates or the reuse by the bacteria of some of the labeled SCFA (23).

The increase of the organic acid labeling was associated with a 32 -fold decrease in blood group antigenicity of the brush border as estimated by the hemagglutination inhibition reaction (Fig. 4A). This finding

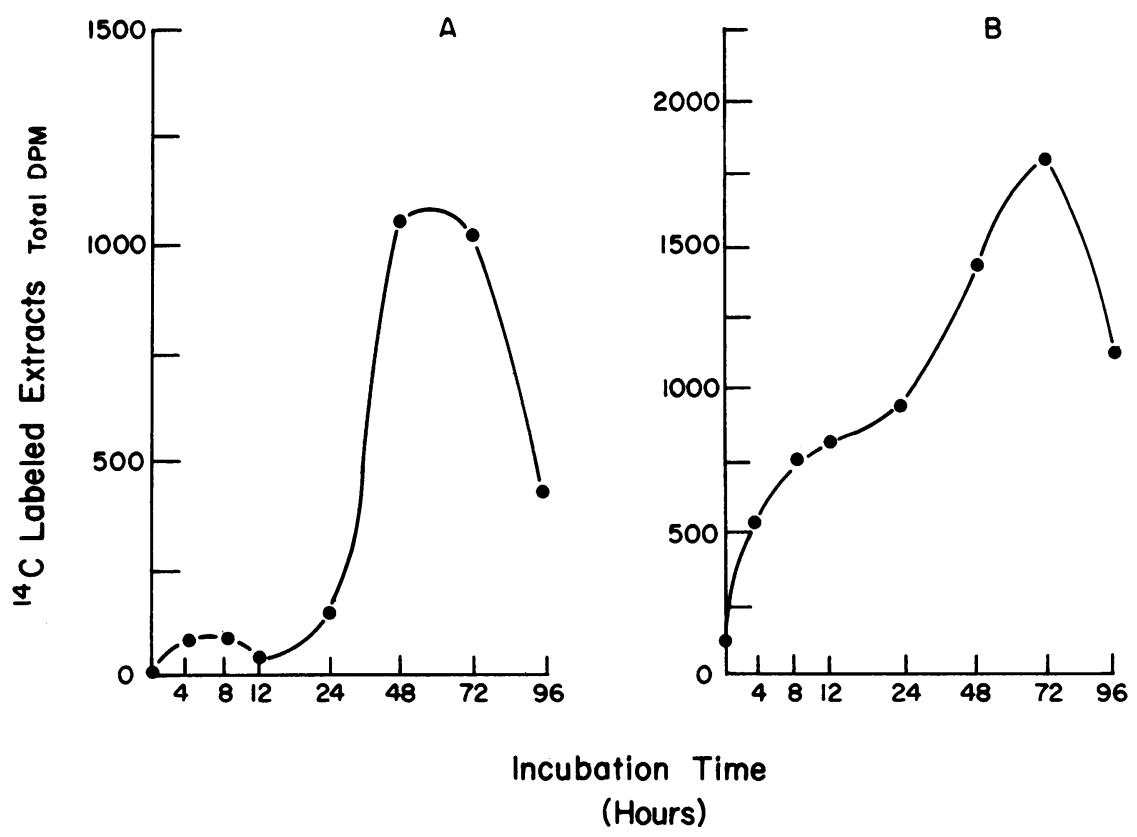

FIGURE 3 Radioactivity of ether extractable organic acids after incubation of blind loop bacteria with (A) mucosal homogenate labeled with $5 \mu \mathrm{Ci}$ of $\mathrm{D}-\left[\mathrm{U}-{ }^{14} \mathrm{C}\right]$ glucosamine and (B) isolated brush borders labeled with $10 \mu \mathrm{Ci}$ of $\mathrm{D}-\left[\mathrm{U}-{ }^{14} \mathrm{C}\right]$ glucosamine. 

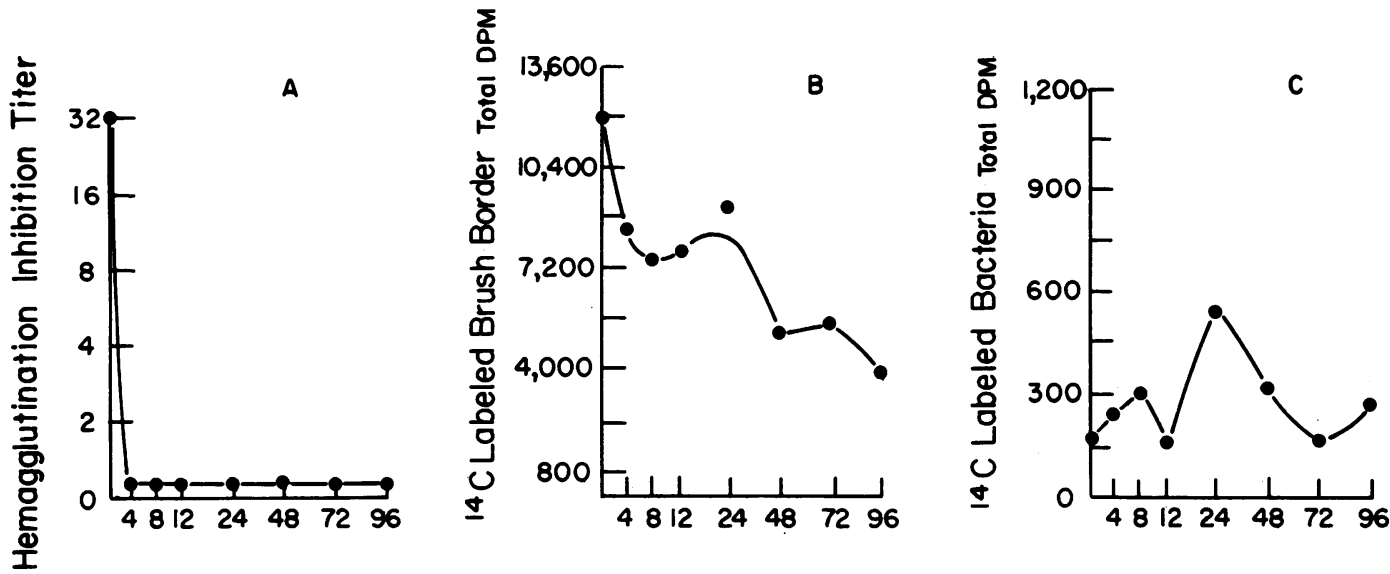

Incubation Time ( Hours)

FIGURE 4 (A) Loss of blood group antigenicity of brush borders after incubation with blind loop bacteria. (B) Decrease in the labeling of incubated brush borders. (C) Radioactivity recovered from incubated blind loop bacteria.

further confirmed that terminal nonreducing sugars of the labeled brush border glycoproteins that are responsible for the blood group antigenicity were readily removed by bacterial glycosidases. As can be seen in Fig. 4B, there was an almost continuous decline in the radioactivity of the glycosylated brush border. Thus, at 96 h, $70 \%$ of the labeling had been removed. Experiments involving hydrolysis of brush borders revealed the decrease of radioactivity was largely due to the substantial removal of labeled sugars, as reflected by the $70 \%$ reduction in labeled hexosamines at $72 \mathrm{~h}$ (Fig. 5A). As further evide'nce of brush border damage, sucrase activity decreased by $60 \%$ at $72 \mathrm{~h}$ (Fig. $5 \mathrm{~B}$ ).

Intraperitoneal injection of $\mathrm{D}-\left[\mathrm{U}_{-}{ }^{14} \mathrm{C}\right]$ glucosamine resulted in an increased production of labeled SCFA. Total radioactivity in bacteria-free supernatants of blind loop contents peaked at $24 \mathrm{~h}$ after injection (Fig. 6A). Concomitantly, SCFA revealed highest ${ }^{14} \mathrm{C}$

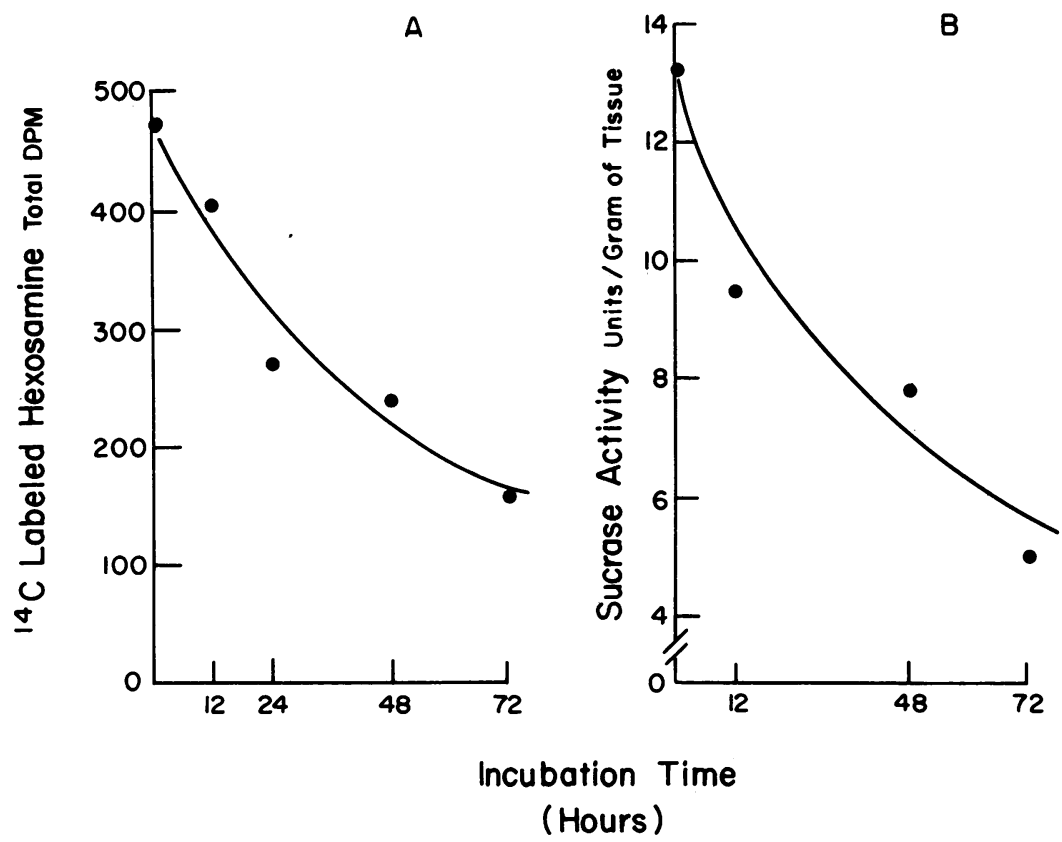

FIGURE 5 (A) Labeled $\left[{ }^{14} \mathrm{C}\right]$ hexosamine from isolated brush borders after incubation with blind loop bacteria. Counts represent total radioactivity of incubated brush borders. (B) Sucrase activity of isolated brush borders after incubation with blind loop bacteria. 

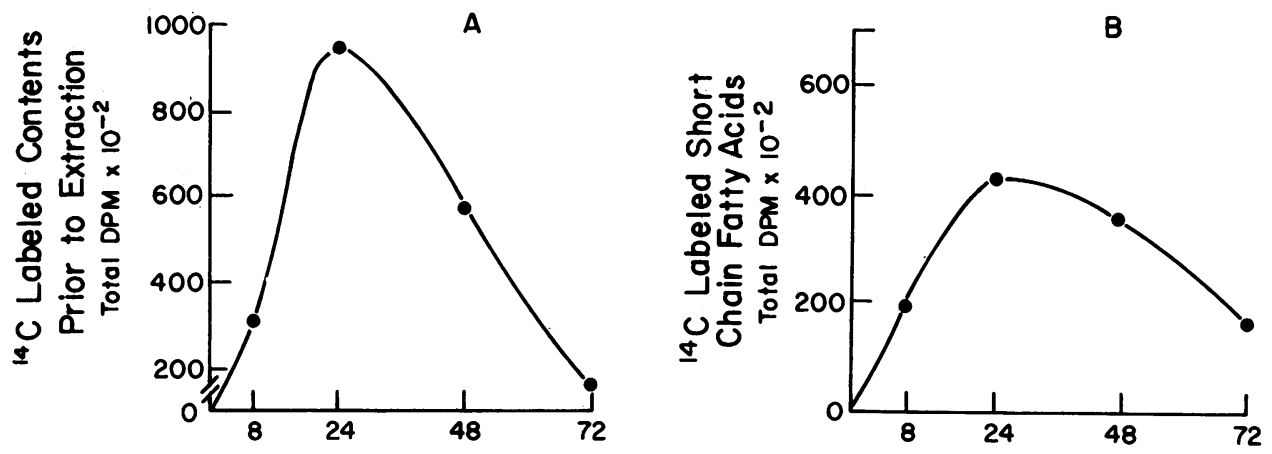

Hours Post Injection

FIGURE 6 Radioactivity recovered from jejunal self-filling blind loop segments after intraperitoneal injection of $\mathrm{D}-\left[\mathrm{U}-{ }^{14} \mathrm{C}\right]$ glucosamine. (A) Total radioactivity recovered from bacteria-free supernates before extraction. (B) Total radioactivity incorporated into ether extractable SCFA.

incorporation at $24 \mathrm{~h}$ (Fig. 6B). As estimated from the counts present in the bacteria-free supernate before ether extraction and SCFA analysis, $56 \pm 4.1 \%$ of the radioactivity was incorporated into SCFA, based on average incorporation values for each time interval. Gas chromatographic analysis showed that $98 \%$ of the radioactivity incorporated into SCFA were in acetic, propionic, and butyric acids (Table II). These acids are largely derived from carbohydrate fermentation. The remaining SCFA were divided among isobutyric, isovaleric, and valeric acids. The branched SCFA isobutyric and isovaleric acids are derivative products from transformation of hexosamines or oxidative deamination of aminoacids $(14,23)$.

\section{DISCUSSION}

A variety of bacteria have been shown to produce blood group degrading enzymes in culture. The blood group A degrading $\alpha$ - $N$-acetylgalactosaminidase has been isolated from Clostridium tertium and Clostridium perfringens; the blood group B degrading enzyme $\alpha$-galactosidase is produced by the anaerobic bacteria Clostridium maebashi (24). $\alpha$-Fucosidase, which destroys the blood group $\mathrm{H}$ antigenicity has

TABLE II

SCFA Analysis in Self-filling Blind Loop Contents*

\begin{tabular}{lc}
\hline \multicolumn{1}{c}{ SCFA } & $\begin{array}{c}\text { Percentage of total } \\
\text { radioactivity }\end{array}$ \\
\hline Acetic & $68.65 \pm 4.46$ \\
Propionic & $17.66 \pm 2.35$ \\
Butyric & $12.55 \pm 1.46$ \\
Isobutyric & $0.59 \pm 0.59$ \\
Isovaleric & $2.14 \pm 0.99$ \\
Valeric & $1.30 \pm 0.56$ \\
\hline
\end{tabular}

* Mean \pm SE. been identified in cultures of Bacillus cereus and Bacillus fulminans (25). These blood group degrading enzymes, as well as other active glycosidases have also been reported in the regions of the intestine populated by elevated concentration of bacteria such as the cecal or fecal material (1-3). In small bowel contents, Witebski et al. (26) found a decrease in the titer of blood group A antigenicity in one patient affected of lymphogranuloma of the large bowel and in another with a colonic fistulae. He hypothesized that perhaps a relation exists between blood group destroying factors and an abnormal bacterial invasion of the upper intestinal tract. Hitherto, however, glycoprotein degrading enzymes have not been identified in detail in the abnormal small bowel of patients or experimentally induced pathological condition. The present experimental study shows evidence of high levels of glycoprotein degrading enzymes in contents of blind loop rats.

The experiment with crude contents revealed that the $p$-nitrophenylglycoside was readily hydrolyzed by a blind loop $\alpha-N$-acetylgalactosaminidase. Similarly, partially purified self-filling blind loop contents revealed very high activities of $\alpha-N$-acetylgalactosaminidase. This glycosidase could potentially destroy the blood group A antigenicity of small intestinal glycoproteins. A noteworthy fact is that blood group glycosidases identified in cultures of enteric bacteria have shown different degrading abilities on synthetic and natural substrates. Hoskins et al. (27) isolated in fecal bacteria a blood group B $\alpha$-galactosidase that failed to split off the $\alpha$-nitrophenylgalactoside. In cultures of C. perfringens, an anaerobe frequently found in blind loops, an $\mathrm{H}$ degrading $\alpha$-fucosidase active against natural glycoproteins was distinct from the $p$-nitrophenylfucosidase (28). Conversely, the blood group A and nonblood group degrading glycosidases isolated thus far from enteric bacteria have shown activity 
against the synthetic and natural substate as well. Hence, McGuire et al. purified from $C$. perfringens a group A $\alpha-N$-acetylgalactosaminidase that hydrolyzed the $p$-nitrophenylglycoside and also removed the acetylaminosugar from submaxillary glycoproteins (29). The same enteric bacteria produced a nonblood group $\beta-N$-acetylglucosaminidase with activity against both substrates. In our study, in addition to the blood group A $\alpha-N$-acetylgalactosaminidase, blind loop fluid contained significant levels of $\beta-N$-acetylglucosaminidase, a glycosidase that acts on nonterminal residues of the oligosaccharide chain. This observation suggests that akin to cecal contents, blind loop contents contain blood and nonblood group glycosidases able to act on the different sugars and linkages that compose the carbohydrate moiety of small intestinal glycoproteins $(8,9)$.

The $\alpha$ - $N$-acetylgalactosaminidase recovered from self-filling blind loop segments appears to originate in bacteria. Contents from normal jejunum and selfemptying segments had very low activities of this enzyme. The administration to blind loop rats of chloromycetin and polymyxin, an antibiotic combination that would act on both aerobic and anaerobic bacteria, confirmed this assumption. The trial resulted in a dramatic reduction of the glycosidase level. In accord with previous findings, however, it is likely that only a small proportion of the anaerobic bacteria was responsible for the production of the blood group degrading enzyme (30).

The partially purified blind loop contents were similarly active against small intestinal glycoproteins. The destruction of the blood group $\mathrm{A}$ antigenicity from brush border preparations was probably due to removal from the oligosaccharide chains of the terminal nonreducing $N$-acetylgalactosamine, the sugar determinant of A reactivity. Indeed, the in vitro experiments with labeled brush border glycoproteins revealed that hexosamines are highly reduced from the brush border after exposure to the blind loop bacteria. Further evidence that brush border glycoproteins are also altered was demonstrated by the marked decrease in sucrase activity. Brush border disaccharidases have been shown by Kelly and Alpers (31) to possess blood group antigenicity. However, decreases in sucrase activity cannot be definitely correlated with the loss of blood group antigenicity. Brush border glycoproteins other than disaccharidases may also possess blood group antigenicity.

The removal of sugars from the brush border preparation becomes significant in view of the recent findings by Jonas et al. (32). Using injected radiolabeled glucosamine and a double isotope technique to measure turnover, these investigators demonstrated an increased degradation of glycoproteins in brush borders obtained from blind loop rats. The carbo- hydrate composition of the brush border, however, was unchanged from controls. It is likely that endogenous compensatory synthesis partly makes up the loss of sugars from the oligosaccharide chains. This appears to be corroborated by our findings indicating similar antigenicity in brush borders from blind loop and from proximal and distal segments.

The action of the bacterial glycosidases may not be confined exclusively to the brush border damage. It appears probable that these degrading enzymes function in a more general manner, directing the degrading process against various intestinal glycoproteins. In addition to the brush border glycoproteins, there is the secreted glycoprotein rich in carbohydrate. The loss of the blood group A reactivity of the crude mucosal supernate might therefore have also resulted from hydrolysis of the carbohydrate moiety of secreted intestinal glycoproteins.

Finally, the in vitro and in vivo experiments with labeled glycoproteins revealed that by means of the glycosidase action, blind loop bacteria utilize and convert removed sugars into organic acids, i.e., SCFA and in the likely resultant products, carbon dioxide and energy. These findings are reminiscent of previous studies in cecal and rumen physiology which show membrane mucopolysaccharide transformation into SCFA $(33,34)$. It also explains why the presence of high levels of fasting SCFA in blind loop contents fails to show any increase after administration of a meal rich in carbohydrates (14). The luminal blind loop bacteria could remove sugars from the mucosal brush border or from luminally secreted glycoproteins and shed cell glycoproteins. Thus, blind loop bacteria encounter in the oligosaccharide chains of small intestinal glycoproteins ubiquitous and suitable nutrients for growth and adaptation in the luminal content. The ability to obtain and utilize host's substances would confer the blind loop bacteria with biological advantage, allowing them the subsistance in the small bowel environment independent of exogenous dietary intake.

\section{ACKNOWLEDGMENTS}

The author is grateful to Dr. Robert G. Strickland for his critical review of the manuscript, and to Mr. Keith Piatt for his technical help.

This study was supported by a Veterans Administration research grant and in part by Research Allocations Funds of the University of New Mexico.

\section{REFERENCES}

1. Hoskins, L. C. 1968. Bacterial degradation of gastrointestinal mucins. II. Bacterial origin of $\mathrm{ABH}(\mathrm{O})$ blood group antigen-destroying enzymes. Gastroenterology. 54: 218-224.

2. Hoskins, L. C. 1969. Ecological studies of intestinal bacteria. Relation between the specificity of fecal ABO blood group antigen-degrading enzymes from enteric 
bacteria and the ABO blood group of the human host. J. Clin. Invest. 48: 664-673.

3. Prizont, R., N. Konigsberg, and D. Aminoff. 1976. Glycosidase activity in the rat cecal content. Gastroenterology. 70: 928. (Abstr.)

4. Gracey, M., V. Burke, and A. Oshin. 1971. Bacteria, bile salts, and intestinal monosaccharide malabsorption. Gut. 12: $683-692$.

5. Toskes, P. P., R. A. Giannella, H. R. Jervis, W. R. Rout, and A. Takeuchi. 1975. Small intestinal mucosal injury in the experimental blind loop syndrome. Light and electron-microscopic and histochemical studies. Gastroenterology. 68: 1193-1203.

6. Ament, M. E., S. S. Shimoda, D. R. Saunders, and C. E. Rubin. 1972. Pathogenesis of steatorrhea in three cases of small intestinal stasis syndrome. Gastroenterology. 63: 728-747.

7. Giannella, R. A., W. R. Rout, and P. P. Toskes. 1974. Jejunal brush border injury and impaired sugar and aminoacid uptake in the blind loop syndrome. Gastroenterology. 67: 965-974.

8. Jobbal, I., D. I. C. Kells, G. Forstner, and J. Forstner. 1976. Human intestinal goblet cell mucin. Can. J. Biochem. 54: 707-716.

9. Forstner, J. F. 1978. Intestinal mucin in health and disease. Digestion. 17: 234-263.

10. Lambert, R. 1965. Surgery of the digestive system in the rat. Charles C Thomas, Springfield, Ill. 455-456.

11. Kim, Y. S., and J. Perdomo. 1972. Glycoprotein biosynthesis in small intestine. III. Enzymatic basis for the difference in the antigenicity of mucins. J. Clin. Invest. 51: 1135-1145.

12. Forstner, G., S. M. Sabesin, and K. J. Isselbacher. 1968. Rat intestinal microvillus membranes: purification and biochemical characterization. Biochem. J. 106: 381-390.

13. Forstner, G. G. 1970. $1{ }^{14} \mathrm{C}$ Glucosamine incorporation by subcellular fractions of small intestinal mucosa. Identification by precursor labeling of three functionally distinct glycoprotein classes. J. Biol. Chem. 245: 3584-3592.

14. Prizont, R., J. S. Whitehead, and Y. S. Kim. 1975. Short chain fatty acids in rats with jejunal blind loops. I. Analysis of SCFA in small intestine, cecum, feces and plasma. Gastroenterology. 69: 1254-1264.

15. Dahlquist, A. 1964. Method for assay of intestinal disaccharidases. Anal. Biochem. 7: 18-25.

16. Bahl, O. M., and K. M. L. Agrawal. 1968. Glycosidases of phaseoulus vulgaris. I. Isolation and characterization of $\beta$ - $N$-acetylglucosaminidase. J. Biol. Chem. 243: 98-102.

17. Whitehead, J. S., Y. S. Kim, and R. Prizont. 1976. A simple quantitative method to determine short chain fatty acid levels in biological fluids. Clin. Chim. Acta. 72: 315318.

18. van der Kamer, J. H., H. Bokkel Huinink, and H. A. Weyers. 1949. Rapid method for determination of fat in feces. J. Biol. Chem. 193: 265-275.
19. Lowry, O. M., N. J. Rosenbrough, A. L. Farr, and R. J. Randall. 1951. Protein measurement with the Folin phenol reagent. J. Biol. Chem. 193: 265-275.

20. Siegel, S. 1956. Non-parametrical Statistics for the Behaviorial Sciences. McGraw-Hill Book Co. New York. 116.

21. Spiro, R. G. 1973. Study of the carbohydrates of glycoproteins. Methods Enzymol. 28: 3.

22. Hungate, R. E. 1966. The Rumen and Its Microbes. Academic Press, Inc., New York.

23. Allison, M. J., J. A. Bucklin, and I. M. Robinson. 1966. Importance of the isovalerate carboxylation pathway of leucine biosynthesis in the rumen. Appl. Microbiol. 14: 807-814.

24. Iseki, S., K. Rurukawa, and S. Yamamoto. 1959. B substance-decomposing enzyme produced by an anaerobic bacterium. II. Chemical action of the B-decomposing enzyme. Proc. Jpn. Acad. 25: 513-517.

25. Iseki, S. 1977. ABH blood group substances in living organisms. In human blood groups. 5th International Convocation of Immunology. Karger, Basal. 126-133.

26. Witebski, E., and E. Neter. 1935. Distribution of blood group properties and blood group property destroying factors in the intestinal tract of man. J. Exp. Med. 62: 589-598.

27. Hoskins, L. C., and E. T. Boulding. 1976. Degradation of blood group antigens in human colon ecosystems. In vitro production of $\mathrm{ABH}$ blood group-degrading enzymes by enteric bacteria. J. Clin. Invest. 57: 63-73.

28. Aminoff, D., and K. Furukawa. 1970. Enzymes that destroy blood group specificity. I. Purification and properties of a $\alpha$-L-fucosidase from Clostridium perfringens. J. Biol. Chem. 245: 1959-1669.

29. McGuire, E. J., S. Chipowsky, and S. Roseman. 1973. $\beta$ - $N$-acetylglucosaminidase, $\alpha-N$-acetylgalactosaminidase and $\beta$-galactosidase from Clostridium perfringens. Methods Enzymol. 28: 755-763.

30. Hoskins, L. C., and E. T. Boulding. 1976. Degration of blood group antigens in human colon ecosystems. II. A gene interaction in man that affects the fecal population density of certain enteric bacteria. J. Clin. Invest. 57: 74-82.

31. Kelly, J. J., and D. H. Alpers. 1973. Blood group antigenicity of purified human intestinal disaccharidases. J. Biol. Chem. 248: 8216-8221.

32. Jonas, A., P. R. Falanagan, and G. G. Forstner. 1977. Pathogenesis of mucosal injury in the blind loop syndrome. Brush border enzyme activity and glycoprotein degradation. J. Clin. Invest. 60: 1321-1330.

33. Yang, M. G., W. G. Bergen, A. E. Sculthorpe, and O. Mickelsen. 1972. Utilization of ${ }^{14} \mathrm{C}$-labeled $\mathrm{E}$. Coli by the rat cecum and after force-feeding. Proc. Soc. Exp. Biol. Med. 139: 1312-1316.

34. Hoogenraad, J. H., F. J. R. Hird, R. G. White, et al. 1970. Utilization of ${ }^{14} \mathrm{C}$-labeled Bacillus subtilis and Escherichia coli by sheep. Br.J. Nutr. 24: 129-144. 